\title{
Impaired aortic distensibility measured by computed tomography is associated with the severity of coronary artery disease
}

\author{
Naser Ahmadi • Vahid Nabavi · Fereshteh Hajsadeghi · Ferdinand Flores • \\ Shahdad Azmoon - Hussain Ismaeel • David Shavelle • Song S. Mao • \\ Ramin Ebrahimi $\cdot$ Matthew J. Budoff
}

Received: 15 January 2010/Accepted: 28 July 2010/Published online: 15 August 2010

(C) The Author(s) 2010. This article is published with open access at Springerlink.com

\begin{abstract}
Impaired aortic distensibility index (ADI) is associated with cardiovascular risk factors. This study evaluates the relation of ADI measured by computed tomographic angiography (CTA) with the severity of coronary atherosclerosis in subjects with suspected coronary artery disease (CAD). Two hundred and twenty-nine subjects, age $63 \pm 9$ years, $42 \%$ female, underwent coronary artery calcium (CAC) scanning and CTA, and their ADI and Framingham risk score (FRS) were measured. End-systolic and enddiastolic (ED) cross-sectional-area(CSA) of ascending-aorta (AAo) was measured 15-mm above the leftmain coronary ostium. ADI was defined as: [( $\Delta$ lumen$\mathrm{CSA}) /($ lumen-CSA in ED $\times$ systemic-pulse-pressure) $\times 10^{3}$ ]. ADI measured by $2 \mathrm{D}$-trans-thoracic echocardiography (TTE) was compared with CTA-
\end{abstract}

N. Ahmadi ( $\bowtie) \cdot$ V. Nabavi · F. Hajsadeghi ·

F. Flores - H. Ismaeel - S. S. Mao - M. J. Budoff

Los Angeles Biomedical Research Institute,

Harbor-UCLA Medical Center, 1124 W. Carson Street,

RB2, Torrance, CA 90502, USA

e-mail: nahmadi@labiomed.org

R. Ebrahimi

Greater Los Angeles VA Medical Center,

UCLA, School of Medicine, Los Angeles, CA, USA

D. Shavelle

University of Southern California, Los Angeles, CA, USA

S. Azmoon

New York Medical College, Valhalla, NY, USA measured ADI in 26 subjects without CAC. CAC was defined as $0,1-100,101-400$ and $400+$. CAD was defined as luminal stenosis $0,1-49 \%$ and $50 \%+$. There was an excellent correlation between CTA- and TTE-measured ADI $\left(r^{2}=0.94, P=0.0001\right)$. ADI decreased from CAC 0 to CAC 400+; similarly from FRS $1-9 \%$ to FRS $20 \%+(P<0.05)$. After adjustment for risk factors, the relative risk for each standard deviation decrease in ADI was 1.66 for CAC 1-100, 2.26 for CAC $101-400$ and 2.32 for CAC $400+$ as compared to CAC 0; similarly, 2.36 for non-obstructive $\mathrm{CAD}$ and 2.67 for obstructive $\mathrm{CAD}$ as compared to normal coronaries. The area under the ROC-curve to predict significant CAD was 0.68 for FRS, 0.75 for ADI, 0.81 for CAC and 0.86 for the combination $(P<$ 0.05). Impaired aortic distensibility strongly correlates with the severity of coronary atherosclerosis. Addition of ADI to CAC and traditional risk factors provides incremental value to predict at-risk individuals.

Keywords Aortic distensibility index - Computed tomographic angiography $\cdot$ Coronary artery calcium score $\cdot$ 2D Trans-thoracic echocardiography

\section{Introduction}

Vascular dysfunction has been shown to be an independent predictor of adverse cardiovascular events [1-3]. Impaired vascular function is associated 
with coronary artery disease [4], hypertension [5], diabetes [6, 7], and hypercholesterolemia [8-10].

Arterial distensibility, a measure of vascular function, can serve as a marker of coronary heart disease risk in humans [11, 12], In addition animal studies suggest that reduced arterial distensibility is an early sign of atherosclerotic change [13]. Previous studies revealed an inverse relationship between aortic distensibility and cardiovascular risk factors and may predict outcome [14-16].

The aorta maintains low left ventricular after-load, promotes optimal subendocardial coronary blood flow [17], and transforms pulsatile into more luminar blood flow. Impaired aortic distensibility leads to higher left ventricular systolic pressures, diminished subendocardial blood supply [17] and may ultimately contribute to left ventricular dysfunction $[18,19]$.

Coronary artery calcium (CAC) is a marker of overall atherosclerotic burden and correlates well with the total plaque burden, the presence of obstructive coronary artery disease (CAD) and future cardiovascular events in both genders across ethnicities [20-22]. Systemic vascular dysfunction measured through reactive hyperemia procedure is strongly correlated with increasing Framingham risk score (FRS) and CAC independent of age, sex, and traditional cardiac risk factors and is superior to FRS for the prediction of significant CAC [23].

This study evaluates whether impaired aortic distensibility index (ADI) is associated with the severity of coronary atherosclerosis in at-risk individuals.

\section{Methods}

Subjects and study design

Two hundred and twenty-nine consecutive subjects referred for coronary artery calcium (CAC) scanning and CTA for suspected coronary artery disease (CAD) were enrolled. Patients with established cardiovascular disease, stroke, diabetic retinopathy, Raynaud's syndrome, infection, cancer, immunosuppression, systemic inflammation, advanced renal or liver disease, creatinine $>1.4 \mathrm{mg} / \mathrm{dl}$, and triglyceride $>400 \mathrm{mg} / \mathrm{dl}$ were excluded. In a sub-study, 26 patients with normal coronaries and CAC 0 underwent $2 \mathrm{D}$ trans-thoracic echocardiography (TTE). The ascending aorta diameter and cross-sectional area measured by CTA and TTE were compared. Risk factors were determined, and FRS was calculated to assess the risk of developing total coronary disease events (angina, myocardial infarction, or cardiovascular death) over the next 10 years [24].

CAC scanning

The coronary arteries were imaged with 30-40 contiguous $3 \mathrm{~mm}$ slices during mid-diastole using ECG-triggering during a $15 \mathrm{~s}$ breath hold. CAC was considered present in a coronary artery when a density of $>130$ Hounsfield units (HU) was detected in $\geq 3$ contiguous pixels $\left(>1 \mathrm{~mm}^{2}\right.$ ) overlying that coronary artery and quantified using the previously described Agatston scoring method [25].

\section{Cardiac CTA}

Beta blockers were administered for pulses greater than $65 \mathrm{bpm}$. CTA was performed according to standard clinical technique with retrospective ECG gating and ECG pulsing applied. Mean heart rate during the scan was $57 \pm 2 \mathrm{bpm}$.

\section{Data acquisition}

A 64- Multi-detector Computed Tomography (MDCT) scanner (Lightspeed VCT, General Electric Healthcare Technologies, Milwaukee, WI) was used for all subjects. Imaging was started 1 inch above the left main ostium and continued to 1 inch below the bottom of the heart. The following imaging and reconstruction parameters were applied: data acquisition collimation $0.625 \mathrm{~mm} \times 64=4 \mathrm{~cm} ; 120 \mathrm{kVp} ; 220-670 \mathrm{mAs}$; pitch $0.18-0.24$ (depending on heart rate); rotation time $0.35 \mathrm{~s}$; slice width $0.625 \mathrm{~mm}$; matrix $512 \times 512$ and pixel size $0.39 \mathrm{~mm}^{2}$. ECG-triggered dose modulation was applied in each case with 400-600 mA in 60-80\% R-R interval and 250-350 $\mathrm{mA}$ for the rest of the cardiac cycle ( 81 to $59 \%$ of the next cycle).

Cardiac data were reconstructed from 5 to $95 \%$ of $\mathrm{R}-\mathrm{R}$ interval and with $10 \%$ intervals. Coronary vessels were reviewed (AW Volume Share ${ }^{\mathrm{TM}}$, GE Medical Systems, Milwaukee, WI) and volume renderings and curved multi-planar reformations were done. CAC was defined as CAC 0, CAC 1-100, CAC 101-400 and CAC $400+$. CAD was defined as normal coronaries, non-obstructive and obstructive CAD (luminal 
stenosis 1-49 and 50\%, respectively). Two skilled cardiologists blinded to the clinical data measured the CAC and interpreted CTA separately.

\section{Measurements}

\section{Cardiac CTA}

The principle of aortic distensibility measurement is illustrated in Fig. 1. The window level and width of 300 and $800 \mathrm{HU}$ was used. True CSA and diameter of ascending aorta (AAo) was measured both manually and with the automated software (Workstation AW 4.4, GE Medical Systems, Milwaukee, WI) using the aligned and adjusted planes. The CSA and diameter of AAo were measurements $15 \mathrm{~mm}$ above the ostium of left main artery [26]. AAo diameter and CSA were measured from 5 to $95 \%$ of the R-R interval in $10 \%$ increments. Maximum AAo diameter and CSA was observed at end-systolic phase, 35\% of R-R interval in individuals with a heart rate $\leq 60 \mathrm{bpm}$. AAo diameter and CSA decreased linearly from endsystole to end-diastole phases from 35 to $95 \%$ of R-R interval; which the minimum AAo diameter and CSA was observed at the end-diastolic $(95 \%$ of $\mathrm{R}-\mathrm{R}$ interval) phase.

Consensus was reached with a third expert measurement in case of disagreements between the manual and automated measures ( 2 cases).

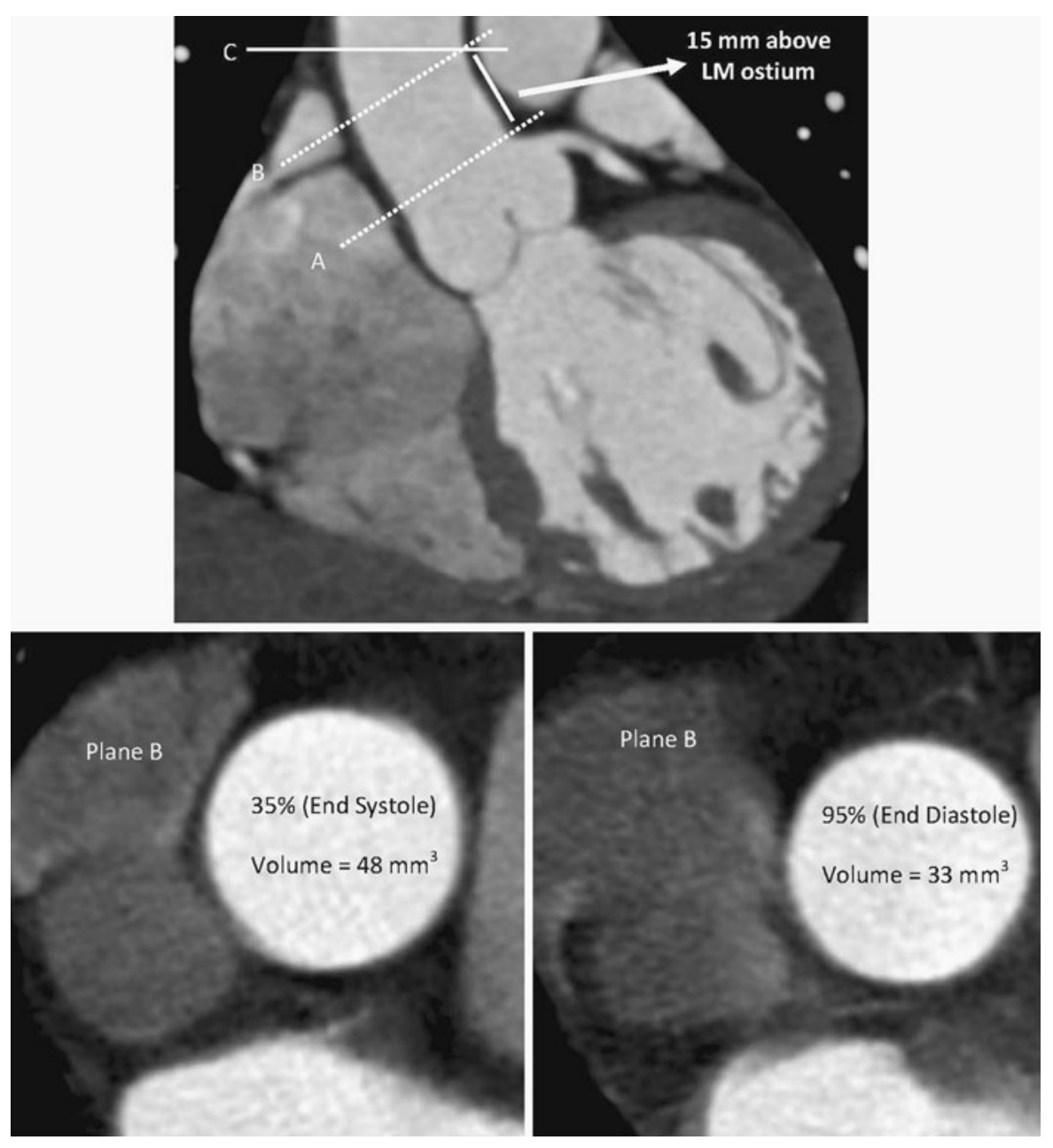

Fig. 1 Changes in the volume of ascending aorta (AAo) at the end systolic and end diastolic phase, $35 \%$ and $95 \%$ of R-R interval respectively, $15 \mathrm{~mm}$ above LM ostium using axial and coronal views. Using axial image, AAo image $15 \mathrm{~mm}$ above
LM ostium was assessed $(C)$, then perpendicular diameter and volume of AAo was measured using coronal and oblique views $(B)$ at end systole and diastole, respectively 
ADI was defined as: $[\mathrm{ADI}=(\Delta$ lumen $\mathrm{AAo}$ $\mathrm{CSA}) /($ end-diastole AAo CSA $\times$ systemic pulse pressure) $\left.\times 10^{3}\right][27,28]$. $\Delta$ lumen AAo CSA is defined as: end-systolic AAo CSA - end-diastolic AAo CSA. Brachial artery blood pressure was measured before and after CTA acquisition, and the mean value was calculated.

Trans-thoracic echocardiography

In a sub-study, 26 subjects with normal coronaries and CAC 0 underwent TTE within a week after cardiac CTA. AAo diameter was measured $15 \mathrm{~mm}$ above sinotubular junction in the M-mode tracings, guided by the two-dimensional long parasternal axis [29] using Hewlett-Packard Sonos 5,500 echocardiographic system (Hewlett-Packard Corporation, Palo Alto, CA). Simultaneous recording of the ECG during TTE permitted evaluation of changes in AAo diameter during various phases of cardiac cycle, and reliable comparison with CTA measured AAo diameter. AAo cross section area (CSA) was calculated from 35\%, end-systolic-, and 95\%, end-diastolic-phase, of echocardiogram measured diameter with the assumption that the CSA is circular $\left(\right.$ area $\left.=(\text { diameter } / 2)^{2} \times(\pi)\right)$. TTE and CTA measured ADI was driven from calculated and measured AAo CSA, respectively.

\section{Statistical analysis}

Mean \pm SD and proportions were used to summarize the characteristics of the study group. Continuous variables were compared by ANOVA, and categorical variables were compared by the Kruskal-Wallis multivariate analysis. Inter-observer and inter-modality (CTA vs. TTE) variability of AAo diameter measurement were calculated using intra-class correlation coefficient (ICC), and Bland \& Altman plots [30]. Relative risk regression analyses were employed to assess the association between the severity of CAC and ADI, also the association between ADI and CAD before and after adjustment for conventional cardiovascular risk factors, as well as for Framingham risk score. ROC curves were constructed and the area under the ROC curve (AUC) was calculated to predict the ability of each model to detect a) significant CAC (CAC 100+), and B) significant CAD (obstructive CAD), respectively. All statistical analyses were performed with PASW version 18.0 (SPSS Institute Inc, Chicago, IL, http://www.spss.com). The level of significance was set at $P<0.05$ (two-tailed). The study protocol was approved by the IRB Committee Board of the Los Angeles Biomedical Research Institute at Harbor UCLA, Torrance, California and all patients provided written informed consent.

\section{Results}

Aortic distensibility index (ADI)

CTA measured ADI was compared to the TTE measured ADI. There was excellent correlation between CTA and TTE measured ADI $\left(r^{2}=0.94\right.$, ICC $=0.99, P=0.0001)$. However, CTA measured ADI was $3.4 \%$ higher than TTE. (Figure 2a) There was excellent inter-observer agreement in measuring ADI using TTE and CTA. The inter-observer variability was higher with TTE than CTA (Fig. 2b).

Patient characteristics and aortic artery distensibility

Patients were characterized based upon the severity of CAC and placed into one of 4 groups (CAC 0, 1-100, 101-400 and 400+) (Table 1). There were no significant differences in gender, smoking status, diabetes mellitus, hypertension, hypercholesterolemia, lipid profile, and family history of premature CAD between the cohorts. The mean age was higher in patients with significant CAC as compared to normal cohort. The Framingham risk score increased substantially with increasing CAC. In a sub-study in subjects with CAC zero, ADI decreased with the metabolic status from normal cohorts to diabetes mellitus $(P<0.05)$.

There was strong inverse correlation between ADI and CAC $\left(r^{2}=-0.69, P=0.0001\right)$. ADI decreased proportionally from CAC 0 to CAC $1-100$ to CAC 101-400 to CAC 400+ in both genders (Fig. 3a and b). Furthermore, severity of CAC increased incrementally in each FRS category as ADI decreased; similarly, in each ADI category as FRS increased. The highest CAC was noted with the combination of the lowest tertile of ADI and FRS 20\%+; The lowest ADI was observed in subjects with highest CAC and 

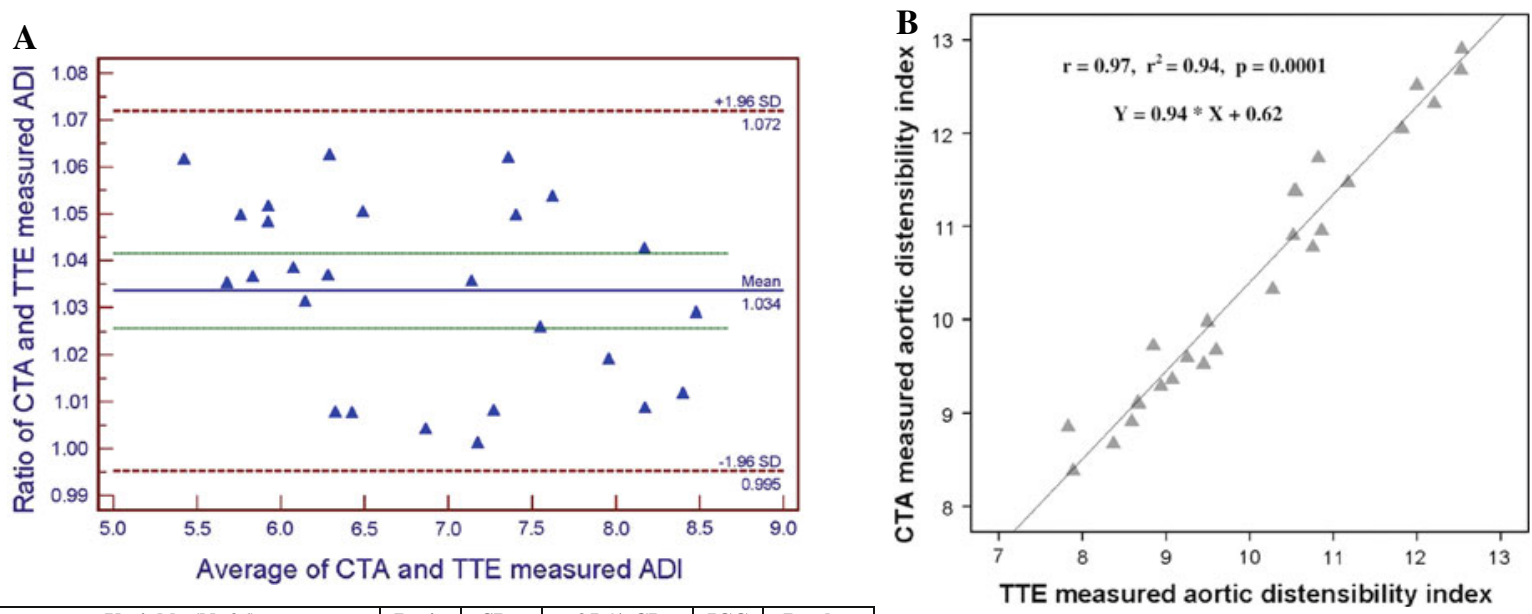

\begin{tabular}{|c|c|c|c|c|c|}
\hline Variable (N=26) & Ratio & SD $_{\mathbf{D}}$ & $\mathbf{9 5}$ \% CI & ICC & P value \\
\hline CTA vs. TTE - AAo ADI & 1.03 & 0.01 & $1.02-1.04$ & 0.99 & 0.0001 \\
\hline Inter-observer -TTE measured AAo ADI & 1.011 & 0.008 & $0.99-1.19$ & 0.98 & 0.0001 \\
\hline Inter-observer -CTA measured AAo ADI & 1.001 & 0.001 & $0.99-1.006$ & 0.99 & 0.0001 \\
\hline
\end{tabular}

Fig. 2 a The variability between TTE and CTA in measured aortic distensibility index. b CTA measured aortic artery distensibility (ADI) correlated well with TTE measured ADI

FRS (Fig. 3b). ADI decreased with the severity of metabolic status in each CAC category in which diabetics with $\mathrm{CAC} 400+$ had the least ADI. (Figure 3c) After adjustment for age, gender, conventional cardiac risk factors, and FRS by relative risk regression analyses, the risk of each standard deviation decrease in ADI was 1.66 for CAC 1-100, 2.26 for CAC $101-400$ and 2.32 for CAC $400+$ as compared to CAC 0. (Table 2) Multivariate regression analysis showed that ADI was an independent predictor of the severity of CAC.

Increasing severity of CAD was associated with increase in CAC and FRS, and decrease in ADI (Table 1). After adjustment for age, gender, conventional cardiac risk factors, and CAC, ADI was independent predictor of significant CAD. (Table 3).

ROC curves were constructed to assess the ability of cardiovascular risk factors and ADI to predict: a) significant CAC, and b) significant CAD. The AUC for proposed models is summarized in Fig. 4. Addition of ADI to FRS increased the area under the ROC curve to predict significant CAC significantly from 0.63 to $0.84(P<0.05)$ and provided the largest contributor to significant CAC prediction. Similarly, addition of ADI to CAC and traditional risk factors increased the area under the ROC curve to predict significant CAD from 0.68 to 0.86 .

\section{Discussion}

The current study demonstrates that: 1. Excellent correlation exists between TTE and CTA measured ADI, 2- ADI decreased with the severity of metabolic status, 3. CTA measured ADI decreased proportionally with the severity of CAC independent of cardiovascular risk factors, and 4. Addition of ADI to FRS improved the ability to detect significant CAC from 0.63 to 0.84 .

There is considerable heterogeneity in the magnitude of vascular dysfunction in individuals with similar risk factor profiles [31, 32]. In this regard, vascular dysfunction may be seen as an important "integrative factor" of the inherent atherosclerotic risk of an individual which takes into account the cumulative effects of various risk and protective factors [31]. In addition to improving risk assessment for the prediction of cardiovascular outcomes, another important application of vascular function assessment is to evaluate response to therapies [33-37].

Arterial distensibility serves as a marker of the structure and function of the artery (i.e. vascular function) and has been shown to diminish with advancing age and with increasing cardiovascular risk factors [38]. Recent studies have demonstrated that oxidative modification of LDL particles, and 
Table 1 Cardiovascular risk factors and the severity of coronary artery calcium

\begin{tabular}{|c|c|c|c|c|c|c|}
\hline Coronary artery calcium & \multicolumn{2}{|c|}{$\begin{array}{l}\text { Normal } \\
(N=78)\end{array}$} & $\begin{array}{l}\text { CAC } 1-100 \\
(N=42)\end{array}$ & $\begin{array}{l}\text { CAC } 101-400 \\
(N=40)\end{array}$ & $\begin{array}{l}\text { CAC } 400+ \\
(N=69)\end{array}$ & $P$ value \\
\hline Age (years) & \multicolumn{2}{|c|}{$55 \pm 10$} & $55 \pm 9$ & $57 \pm 9$ & $61 \pm 8$ & 0.001 \\
\hline Male gender & \multicolumn{2}{|c|}{$67 \%$} & $61 \%$ & $69 \%$ & $68 \%$ & 0.8 \\
\hline Smoking & \multicolumn{2}{|l|}{0} & 0 & $3 \%$ & $3 \%$ & 0.4 \\
\hline Hypertension $^{\dagger}$ & \multicolumn{2}{|c|}{$46 \%$} & $35 \%$ & $57 \%$ & $55 \%$ & 0.2 \\
\hline High cholesterol & \multicolumn{2}{|c|}{$46 \%$} & $41 \%$ & $51 \%$ & $38 \%$ & 0.6 \\
\hline Diabetes mellitus ${ }^{\S}$ & \multicolumn{2}{|c|}{$16 \%$} & $19 \%$ & $19 \%$ & $15 \%$ & 0.7 \\
\hline Family history of $\mathrm{CHD}^{\|}$ & \multicolumn{2}{|c|}{$40 \%$} & $43 \%$ & $57 \%$ & $58 \%$ & 0.1 \\
\hline Statin therapy & \multicolumn{2}{|l|}{$7 \%$} & $12 \%$ & $25 \%$ & $27 \%$ & 0.1 \\
\hline BMI $\left(\mathrm{kg} / \mathrm{m}^{2}\right)$ & \multicolumn{2}{|c|}{$28.1 \pm 3.6$} & $28.8 \pm 3.9$ & $27.6 \pm 5.1$ & $28.4 \pm 4.7$ & 0.6 \\
\hline Total Cholesterol (md/dL) & \multicolumn{2}{|c|}{$191 \pm 42$} & $186 \pm 37$ & $171 \pm 27$ & $178 \pm 43$ & 0.7 \\
\hline HDL-C (mg/dL) & \multicolumn{2}{|c|}{$50 \pm 10$} & $46 \pm 11$ & $50 \pm 14$ & $46 \pm 12$ & 0.5 \\
\hline LDL-C (mg/dL) & \multicolumn{2}{|c|}{$116 \pm 34$} & $120 \pm 26$ & $100 \pm 34$ & $105 \pm 39$ & 0.4 \\
\hline Triglyceride (mg/dL) & \multicolumn{2}{|c|}{$112 \pm 37$} & $115 \pm 28$ & $96 \pm 34$ & $120 \pm 32$ & 0.2 \\
\hline SPB (mm Hg) & \multicolumn{2}{|c|}{$121 \pm 11$} & $129 \pm 10$ & $128 \pm 15$ & $132 \pm 18$ & 0.1 \\
\hline DBP (mm Hg) & \multicolumn{2}{|c|}{$75 \pm 9$} & $76 \pm 8$ & $76 \pm 9$ & $76 \pm 9$ & 0.9 \\
\hline Framingham risk score $(\%)$ & \multicolumn{2}{|c|}{$4.6 \pm 2.6$} & $5.2 \pm 2.8$ & $6.1 \pm 3.3$ & $8.9 \pm 4.6$ & 0.001 \\
\hline AAo $35 \%$ CSA $\left(\mathrm{mm}^{3}\right)$ & 49.7 & $=2.10$ & $48.82 \pm 1.77$ & $47.02 \pm 1.68$ & $46.66 \pm 1.75$ & 0.08 \\
\hline AAo $95 \%$ CSA $\left(\mathrm{mm}^{3}\right)$ & 32.7 & $=1.91$ & $33.34 \pm 1.81$ & $33.69 \pm 1.69$ & $34.14 \pm 2.01$ & 0.8 \\
\hline$\Delta$ AAo CSA/AAo $95 \% \mathrm{CSA}^{\Omega}$ & 0.57 & 0.10 & $0.50 \pm 0.07$ & $0.39 \pm 0.07$ & $0.34 \pm 0.06$ & 0.003 \\
\hline $\mathrm{ADI}^{\Delta}$ & 10.7 & 1.31 & $8.87 \pm 1.13$ & $7.29 \pm 1.09$ & $6.18 \pm 0.92$ & 0.003 \\
\hline CTA-Diagnosed coronary artery & & $\begin{array}{l}\text { Normal } \\
(N=78)\end{array}$ & $\begin{array}{l}\text { CAD } 1-29 \% \\
(N=35)\end{array}$ & $\begin{array}{l}\text { CAD } 30-49 \% \\
(N=61)\end{array}$ & $\begin{array}{l}\text { CAD } 70 \% \\
(N=55)\end{array}$ & $P$ value \\
\hline Framingham risk score $(\%)$ & & $4.6 \pm 2.6$ & $5.2 \pm 2.5$ & $7.4 \pm 4.7$ & $9.8 \pm 5.7$ & 0.001 \\
\hline Coronary artery calcium & & 0 & $43 \pm 26$ & $279 \pm 115$ & $385 \pm 220$ & 0.0001 \\
\hline $\mathrm{ADI}^{\Delta}$ & & $10.7 \pm 1.31$ & $8.62 \pm 1.19$ & $7.26 \pm 1.21$ & $5.71 \pm 1.21$ & 0.0001 \\
\hline
\end{tabular}

Values presented as mean $\pm \mathrm{SD}$ or $\%$

NS $=$ Non-significant $(P>0.05)$

$\dagger$ Self-reported diagnosis of hypertension, prescribed medication for hypertension, or current blood pressure $>140 \mathrm{mmHg}$ systolic or $>90 \mathrm{mmHg}$ diastolic $(>130 / 80 \mathrm{mmHg}$ if diabetic)

* Self-reported diagnosis of high cholesterol, prescribed medication for high cholesterol, or current total cholesterol $>200 \mathrm{mg} / \mathrm{dL}$

$\S$ Self-reported diagnosis of diabetes (type 1 or 2 ) or prescribed medication for diabetes

॥ First degree relative; female $<65$ yrs, male $<55$ years

$\Omega \quad \triangle$ AAo $\mathrm{CSA}=($ AAo $35 \%$ CSA- AAo $95 \%$ CSA $) /$ AAo $95 \%$ CSA

$\Delta \quad \mathrm{ADI}=(\Delta$ AAo $\mathrm{CSA} /$ systemic pulse pressure $) \times 10^{3}$

vascular wall remodeling induced by hyperglycemia may play a pathophysiological role in reducing arterial distensibility and revealed that aortic distensibility decreased with increasing cardiovascular risk factors [6, 8-10, 18, 19, 39].

Previous studies provided evidence that reduced arterial distensibility predicts future cardiovascular events $[10,15,40]$. Haluska et al. studied the association of arterial distensibility and long-term clinical outcome of 719 patients. They reported that impaired arterial distensibility independently correlated with poor outcome in patients with varying degrees of cardiovascular risk, and arterial distensibility can identify patients at risk of future fatal and non-fatal events [41]. Finally, recent studies have shown that functional changes in arteries 

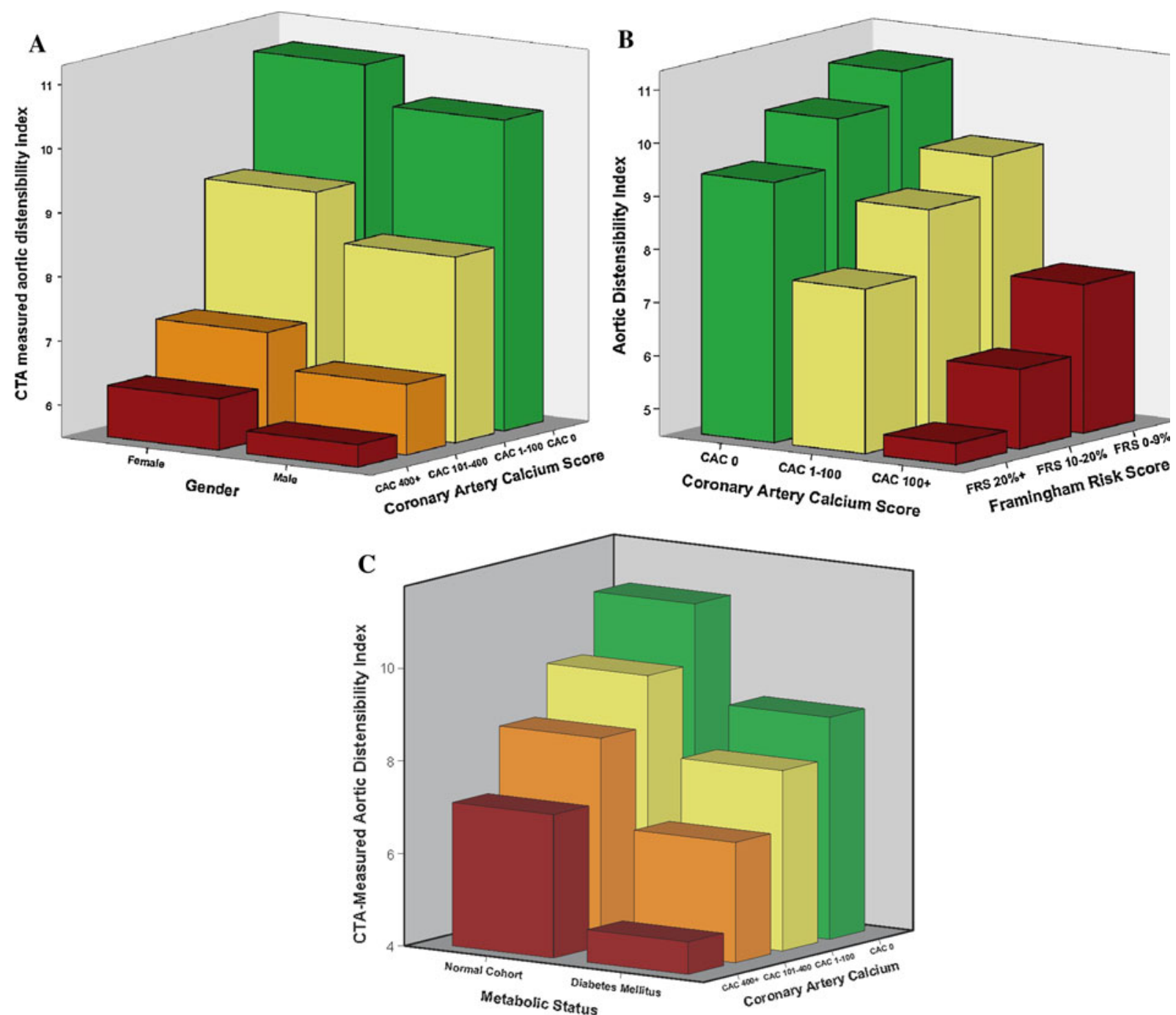

Fig. 3 a Aortic distensibility index (ADI) decreased proportionally with increasing the severity of coronary artery calcium $(\mathrm{CAC})$ in both genders. b ADI decreased with increasing CAC

and Framingham risk score, and $\mathbf{c}$ ADI decreased proportionally with the severity of metabolic status

Table 2 Multivariate relative risk regression analysis of the relationship between the extent of coronary artery calcium and aortic artery distensibility

\begin{tabular}{lllll}
\hline Model & Normal & CAC 1-100 & CAC 101-400 & CAC 400+ \\
\hline $\begin{array}{l}\text { Unadjusted } \\
\text { ADI }^{¥}\end{array}$ & 1 (ref) & $1.57(1.28-1.93), P=0.0001$ & $2.18(1.69-2.82), P=0.0001$ & $2.23(1.78-2.78), P=0.0001$
\end{tabular}

Adjusted for age, gender, diabetes mellitus, hypertension, hypercholesterolemia, family history of CHD, and smoking status

$\mathrm{ADI}^{¥} \quad 1$ (ref) $\quad 1.66(1.39-3.46), P=0.0001 \quad 2.26(1.73-3.28), P=0.0001 \quad 2.32(1.85-5.62), P=0.0001$

Relative risk for each standard deviation (SD) decrease in ADI (SD: 1.2)

precede the development of structural changes and also reverse more quickly in response to therapies [37, 42-44].
Clinical guidelines recommend risk management based on the Framingham score $[45,46]$ followed by goal-directed therapy when necessary [47-49] in 
Table 3 Multivariate relative risk regression analysis of the relationship between the severity of coronary artery diseases and aortic artery distensibility

\begin{tabular}{lccc}
\hline Model & Normal & Non-obstructive CAD & Obstructive CAD \\
\hline Unadjusted & & \\
ADI $^{¥}$ & 1 (ref) & $2.29(1.26-2.75), P=0.0001$ & $2.56(1.94-3.36), P=0.0001$ \\
Adjusted for age, gender, diabetes mellitus, hypertension, hypercholesterolemia, family history of CHD, smoking status and CAC \\
ADI $^{¥}$ & 1 (ref) & $2.36(1.35-3.15), P=0.0001$ & $2.67(1.93-3.56), P=0.0001$ \\
\hline
\end{tabular}

Relative risk for each standard deviation (SD) decrease in ADI (SD: 1.2)

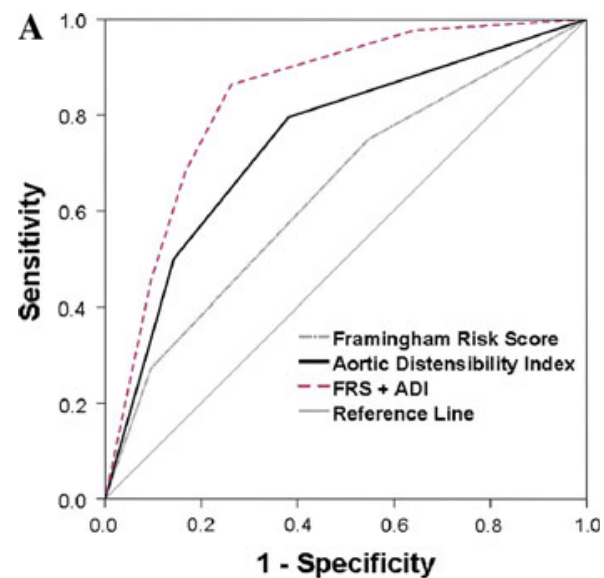

\begin{tabular}{|c|c|c|c|c|}
\hline Variable & $\mathbf{A U C} \pm \mathbf{S D}$ & $95 \% \mathrm{CI}$ & $\mathbf{P}$ & Comparison $\mathbf{P}$ \\
\hline FRS $^{£}$ & $0.63 \pm 0.04$ & $0.53-0.82$ & 0.001 & -- \\
\hline ADI $^{¥}$ & $0.74 \pm 0.04$ & $0.63-0.85$ & 0.0001 & 0.01 \\
\hline FRS + ADI & $0.84 \pm 0.03$ & $0.74-0.91$ & 0.0001 & 0.001 \\
\hline
\end{tabular}

${ }^{£}$ FRS: Framingham risk score - FRS: $1-9 \%, 10-20 \%$, and $20 \%+$

¥ ADI: Aortic distensibility index - per each standard deviation decrease

Fig. 4 a ROC curves for 3 models created to assess the ability of a combination of clinical variables to predict significant coronary artery calcium (CAC 100+). b ROC curves for 4

patients without known prior CAD. Recent studies have showed that FRS has significant limitation in identifying high risk subjects without known CAD $[50,51]$. Current findings revealed that CTA provides an accurate measure for vascular function rather than just anatomical studies; Furthermore, in this study aortic distensibility decreased substantially with the severity of coronary atherosclerosis in both genders. The excellent correlations between impaired aortic distensibility measured by CTA and FRS, and, in particular, the superior independent and incremental value of aortic distensibility for predicting significant coronary atherosclerosis, highlight the role of

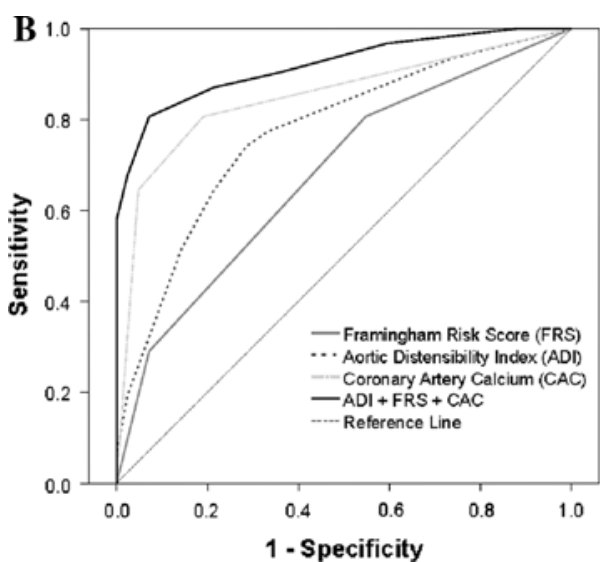

\begin{tabular}{cllll}
\hline Variable & AUC \pm SD & $\mathbf{9 5 \%}$ CI & P & Comparison P \\
\hline FRS $^{\boldsymbol{\varepsilon}}$ & $0.68 \pm 0.04$ & $0.59-0.78$ & 0.0001 & -- \\
ADI $^{\mathbf{\sharp}}$ & $0.75 \pm 0.03$ & $0.67-0.85$ & 0.0001 & 0.001 \\
CAC $^{\boldsymbol{\Omega}}$ & $0.81 \pm 0.02$ & $0.79-0.90$ & 0.0001 & 0.001 \\
FRS + ADI + CAC $^{0.86 \pm 0.01}$ & $0.81-0.92$ & 0.0001 & 0.001 \\
\hline
\end{tabular}

${ }^{£}$ FRS: Framingham risk score - FRS: $1-9 \%, 10-20 \%$, and $20 \%+$

¥ ADI: Aortic distensibility index - per each standard deviation decrease

$\Omega$ CAC: Coronary Artery Calcium- CAC: 0, 1-100, 101-400, and 400+

models created to assess the ability of a combination of clinical variables to predict significant coronary artery disease

vascular function assessment as a part of cardiovascular risk assessment to improve identification of high risk individuals and optimizing patient management.

\section{Limitations}

Beta blockers which are vasoactive medications were administered for heart rates greater than $65 \mathrm{bpm}$. However, recent studies demonstrated that concomitant therapy with non-nitrate vasoactive drugs has no significant effect on vascular function assessment 
[52]. The effect of data acquisition and analysis during a breath-hold is another potential source of error. Nonetheless, the CTA measurements correlated well with the TTE measurements, suggesting that potential errors introduced by non-simultaneous blood pressures and breath-hold are minimal.

\section{Conclusion}

Aortic distensibility measured by CTA correlates well with corresponding values measured by TTE. Impaired aortic distensibility is associated with the severity of coronary atherosclerosis independent of age, gender, and cardiovascular risk factors. Furthermore, addition of ADI to traditional risk factors and CAC provided the largest contribution to detect significant coronary atherosclerosis, and highlights the diagnostic utility of ADI in the early detection and monitoring of patients with atherosclerotic cardiovascular disease by a single noninvasive diagnostic study.

Disclosures Matthew Budoff has a financial disclosure in relationship to this study, as he is on the speaker's bureau for General Electric, whereas other authors have no conflicts to disclose.

Open Access This article is distributed under the terms of the Creative Commons Attribution Noncommercial License which permits any noncommercial use, distribution, and reproduction in any medium, provided the original author(s) and source are credited.

\section{References}

1. Fuster V, Badimon L, Badimon JJ, Chesebro JH (1992) The pathogenesis of coronary artery disease and the acute coronary syndromes (1). N Engl J Med 326(4):242-250

2. Griendling KK, Ushio-Fukai M, Lassegue B, Alexander RW (1997) Angiotensin II signaling in vascular smooth muscle. New concepts. Hypertension 29(1 Pt 2):366-373

3. Vane JR, Anggard EE, Botting RM (1990) Regulatory functions of the vascular endothelium. $N$ Engl J Med 323(1):27-36

4. Bogren HG, Mohiaddin RH, Klipstein RK, Firmin DN, Underwood RS, Rees SR, Longmore DB (1989) The function of the aorta in ischemic heart disease: a magnetic resonance and angiographic study of aortic compliance and blood flow patterns. Am Heart J 118(2):234-247

5. Laurent S, Caviezel B, Beck L, Girerd X, Billaud E, Boutouyrie P, Hoeks A, Safar M (1994) Carotid artery distensibility and distending pressure in hypertensive humans. Hypertension 23(6 Pt 2):878-883

6. Eren M, Gorgulu S, Uslu N, Celik S, Dagdeviren B, Tezel $\mathrm{T}$ (2004) Relation between aortic stiffness and left ventricular diastolic function in patients with hypertension, diabetes, or both. Heart 90(1):37-43

7. Lehmann ED, Gosling RG, Sonksen PH (1992) Arterial wall compliance in diabetes. Diabet Med 9(2):114-119

8. Dart AM, Lacombe F, Yeoh JK, Cameron JD, Jennings GL, Laufer E, Esmore DS (1991) Aortic distensibility in patients with isolated hypercholesterolaemia, coronary artery disease, or cardiac transplant. Lancet 338(8762):270-273

9. Lehmann ED, Watts GF, Gosling RG (1992) Aortic distensibility and hypercholesterolaemia. Lancet 340(8828): 1171-1172

10. Oliver JJ, Webb DJ (2003) Noninvasive assessment of arterial stiffness and risk of atherosclerotic events. Arterioscler Thromb Vasc Biol 23(4):554-566

11. Bank AJ, Wang H, Holte JE, Mullen K, Shammas R, Kubo SH (1996) Contribution of collagen, elastin, and smooth muscle to in vivo human brachial artery wall stress and elastic modulus. Circulation 94(12):3263-3270

12. Sudhir K, Mullen WL, Hausmann D, Fitzgerald PJ, Chou TM, Yock PG, Chatterjee K (1995) Contribution of endothelium-derived nitric oxide to coronary arterial distensibility: an in vivo two-dimensional intravascular ultrasound study. Am Heart J 129(4):726-732

13. Hironaka K, Yano M, Kohno M, Tanigawa T, Obayashi M, Konishi M, Umemoto S, Matsuzaki M (1997) In vivo aortic wall characteristics at the early stage of atherosclerosis in rabbits. Am J Physiol 273(3 Pt 2):H1142-H1147

14. Tentolouris N, Liatis S, Moyssakis I, Tsapogas P, Psallas M, Diakoumopoulou E, Voteas V, Katsilambros N (2003) Aortic distensibility is reduced in subjects with type 2 diabetes and cardiac autonomic neuropathy. Eur J Clin Invest 33(12):1075-1083

15. Cruickshank K, Riste L, Anderson SG, Wright JS, Dunn G, Gosling RG (2002) Aortic pulse-wave velocity and its relationship to mortality in diabetes and glucose intolerance: an integrated index of vascular function? Circulation 106(16):2085-2090

16. Kingwell BA, Waddell TK, Medley TL, Cameron JD, Dart AM (2002) Large artery stiffness predicts ischemic threshold in patients with coronary artery disease. J Am Coll Cardiol 40(4):773-779

17. Belz GG (1995) Elastic properties and windkessel function of the human aorta. Cardiovasc Drugs Ther 9(1):73-83

18. Kelly RP, Tunin R, Kass DA (1992) Effect of reduced aortic compliance on cardiac efficiency and contractile function of in situ canine left ventricle. Circ Res 71(3):490-502

19. Ohtsuka S, Kakihana M, Watanabe H, Sugishita Y (1994) Chronically decreased aortic distensibility causes deterioration of coronary perfusion during increased left ventricular contraction. J Am Coll Cardiol 24(5):1406-1414

20. Detrano R, Guerci AD, Carr JJ, Bild DE, Burke G, Folsom AR, Liu K, Shea S, Szklo M, Bluemke DA, O'Leary DH, Tracy R, Watson K, Wong ND, Kronmal RA (2008) Coronary calcium as a predictor of coronary events in four racial or ethnic groups. N Engl J Med 358(13):1336-1345

21. Brown ER, Kronmal RA, Bluemke DA, Guerci AD, Carr JJ, Goldin J, Detrano R (2008) Coronary calcium coverage 
score: determination, correlates, and predictive accuracy in the Multi-Ethnic Study of Atherosclerosis. Radiology 247(3):669-675

22. Budoff MJ, Nasir K, McClelland RL, Detrano R, Wong N, Blumenthal RS, Kondos G, Kronmal RA (2009) Coronary calcium predicts events better with absolute calcium scores than age-sex-race/ethnicity percentiles: MESA (MultiEthnic Study of Atherosclerosis). J Am Coll Cardiol 53(4):345-352

23. Ahmadi N, Hajsadeghi F, Gul K, Vane J, Usman N, Flores F, Nasir K, Hecht H, Naghavi M, Budoff M (2008) Relations between digital thermal monitoring of vascular function, the Framingham risk score, and coronary artery calcium score. J Cardiovasc Comput Tomogr 2(6):382-388

24. Wilson PW, D'Agostino RB, Levy D, Belanger AM, Silbershatz H, Kannel WB (1998) Prediction of coronary heart disease using risk factor categories. Circulation 97(18):1837-1847

25. Becker CR, Knez A, Jakobs TF, Aydemir S, Becker A, Schoepf UJ, Bruening R, Haberl R, Reiser MF (1999) Detection and quantification of coronary artery calcification with electron-beam and conventional CT. Eur Radiol 9(4):620-624

26. Mao S, Lu B, Takasu J, Oudiz RJ, Budoff MJ (2003) Measurement of the RT interval on ECG records during electron-beam CT. Acad Radiol 10(6):638-643

27. McLeod AL, Newby DE, Northridge DB, Fox KA, Uren NG (2003) Influence of differential vascular remodeling on the coronary vasomotor response. Cardiovasc Res 59(2): 520-526

28. Yamagishi M, Umeno T, Hongo Y, Tsutsui H, Goto Y, Nakatani S, Miyatake K (1997) Intravascular ultrasonic evidence for importance of plaque distribution (eccentric vs circumferential) in determining distensibility of the left anterior descending artery. Am J Cardiol 79(12):1596-1600

29. Stefanadis C, Stratos C, Boudoulas H, Kourouklis C, Toutouzas P (1990) Distensibility of the ascending aorta: comparison of invasive and non-invasive techniques in healthy men and in men with coronary artery disease. Eur Heart J 11(11):990-996

30. Bland JM, Altman DG (1986) Statistical methods for assessing agreement between two methods of clinical measurement. Lancet 1(8476):307-310

31. Halcox JP, Schenke WH, Zalos G, Mincemoyer R, Prasad A, Waclawiw MA, Nour KR, Quyyumi AA (2002) Prognostic value of coronary vascular endothelial dysfunction. Circulation 106(6):653-658

32. Quyyumi AA (2003) Prognostic value of endothelial function. Am J Cardiol 91(12A):19H-24H

33. Binggeli C, Spieker LE, Corti R, Sudano I, Stojanovic V, Hayoz D, Luscher TF, Noll G (2003) Statins enhance postischemic hyperemia in the skin circulation of hypercholesterolemic patients: a monitoring test of endothelial dysfunction for clinical practice? J Am Coll Cardiol 42(1):71-77

34. Celermajer DS (2003) Statins, skin, and the search for a test of endothelial function. J Am Coll Cardiol 42(1):78-80

35. Charbonneau F, Anderson TJ, Title L, Jobin J, Poirier P, Huyhn T, Chan S, Walling A, Hutchison S, Tran T, Lonn E, Buithieu J, Genest J (2008) Modulation of arterial reactivity using amlodipine and atorvastatin measured by ultrasound examination (MARGAUX). Atherosclerosis 197(1):420-427

36. Stulc T, Kasalova Z, Prazny M, Vrablik M, Skrha J, Ceska R (2003) Microvascular reactivity in patients with hypercholesterolemia: effect of lipid lowering treatment. Physiol Res 52(4):439-445

37. Warnholtz A, Wild P, Ostad MA, Elsner V, Stieber F, Schinzel R, Walter U, Peetz D, Lackner K, Blankenberg S, Munzel T (2008) Effects of oral niacin on endothelial dysfunction in patients with coronary artery disease: results of the randomized, double-blind, placebo-controlled INEF study. Atherosclerosis

38. van Popele NM, Grobbee DE, Bots ML, Asmar R, Topouchian J, Reneman RS, Hoeks AP, van der Kuip DA, Hofman A, Witteman JC (2001) Association between arterial stiffness and atherosclerosis: the Rotterdam study. Stroke 32(2):454-460

39. Sun H, Zhong M, Miao Y, Ma X, Gong HP, Tan HW, Zhang Y, Zhang W (2009) Impaired elastic properties of the aorta in fat-fed, streptozotocin-treated rats. Vascular remodeling in diabetic arteries. Cardiology 114(2):107-113

40. Laurent S, Boutouyrie P, Asmar R, Gautier I, Laloux B, Guize L, Ducimetiere P, Benetos A (2001) Aortic stiffness is an independent predictor of all-cause and cardiovascular mortality in hypertensive patients. Hypertension 37(5): 1236-1241

41. Haluska BA, Jeffries L, Carlier S, Marwick TH (2009) Measurement of arterial distensibility and compliance to assess prognosis. Atherosclerosis

42. Shechter M, Issachar A, Marai I, Koren-Morag N, Freinark D, Shahar Y, Shechter A, Feinberg MS (2009) Long-term association of brachial artery flow-mediated vasodilation and cardiovascular events in middle-aged subjects with no apparent heart disease. Int J Cardiol 134(1):52-58

43. Papathanassiou K, Naka KK, Kazakos N, Kanioglou C, Makriyiannis D, Pappas K, Katsouras CS, Liveris K, Kolettis T, Tsatsoulis A, Michalis LK (2009) Pioglitazone vs glimepiride: differential effects on vascular endothelial function in patients with type 2 diabetes. Atherosclerosis 205(1):221-226

44. Ostad MA, Eggeling S, Tschentscher P, Schwedhelm E, Boger R, Wenzel P, Meinertz T, Munzel T, Warnholtz A (2009) Flow-mediated dilation in patients with coronary artery disease is enhanced by high dose atorvastatin compared to combined low dose atorvastatin and ezetimibe: results of the CEZAR study. Atherosclerosis 205(1):227-232

45. Wood D, De Backer G, Faergeman O, Graham I, Mancia G, Pyorala K (1998) Prevention of coronary heart disease in clinical practice. Summary of recommendations of the second joint task force of European and other societies on coronary prevention. J Hypertens 16(10):1407-1414

46. Fedder DO, Koro CE, L'Italien GJ (2002) New National Cholesterol Education Program III guidelines for primary prevention lipid-lowering drug therapy: projected impact on the size, sex, and age distribution of the treatment-eligible population. Circulation 105(2):152-156

47. Third Report of the National Cholesterol Education Program (NCEP) (2002) Expert panel on detection, evaluation, and treatment of high blood cholesterol in adults (Adult Treatment Panel III) final report. Circulation 106(25):3143-3421 
48. Grundy SM, Cleeman JI, Merz CN, Brewer HB Jr, Clark LT, Hunninghake DB, Pasternak RC, Smith SC Jr, Stone NJ (2004) Implications of recent clinical trials for the National Cholesterol Education Program Adult Treatment Panel III guidelines. Circulation 110(2):227-239

49. Smith SC Jr, Greenland P, Grundy SM (2000) AHA conference proceedings. Prevention conference $\mathrm{V}$ : beyond secondary prevention: identifying the high-risk patient for primary prevention: executive summary. American heart association. Circulation 101(1):111-116

50. Khot UN, Khot MB, Bajzer CT, Sapp SK, Ohman EM, Brener SJ, Ellis SG, Lincoff AM, Topol EJ (2003)
Prevalence of conventional risk factors in patients with coronary heart disease. JAMA 290(7):898-904

51. Scridon T, Novaro GM, Bush HS, Asher CR, Dandes E, Kabirdas D, Scridon C, Kuo BT, Whiteman M, Shen MY (2008) Reclassification of patients for aggressive cholesterol treatment: additive value of multislice coronary angiography to the National Cholesterol Education Program guidelines. Clin Cardiol 31(9):419-423

52. Gokce N, Holbrook M, Hunter LM, Palmisano J, Vigalok E, Keaney JF Jr, Vita JA (2002) Acute effects of vasoactive drug treatment on brachial artery reactivity. J Am Coll Cardiol 40(4):761-765 